\title{
Aplikasi Pelayanan Rumah Susun Berbasis Website (Studi Kasus: Rumah Susun Cinta Kasih Tzu Chi)
}

\author{
Mardiansah*¹, Afri liandy $^{2}$, Sukrisna Setiawan ${ }^{3}$, Anita Ratnasari ${ }^{4}$ \\ ${ }^{1,2}$ Universitas Mercu Buana; Jalan”Meruya Selatan No. 1, Meruya Selatan, Kembangan, \\ Meruya Sel., Kembangan, Jakarta Barat, Daerah Khusus Ibukota Jakarta 11650 \\ ${ }^{3}$ Program Studi Sistem Informasi, Fakultas Ilmu Komputer \\ e-mail: *11mardiansahacc@gmail.com, ${ }^{2}$ afriliandy@gmail.com, ${ }^{3}$ ovikriz@gmail.com, \\ ${ }^{4}$ anita.ratnasari@mercubuana.ac.id
}

\begin{abstract}
Abstrak
Rumah Susun Cinta Kasih Tzu Chi merupakan rumah susun yang di kelola oleh pihak swasta. Rumah Susun tersebut menerapkan sistem manajemen pelayanan secara manual, sehingga terdapat beberapa kendala yang menghambat proses pelayanan terhadap penghuni rumah susun, yaitu belum terdapat sistem pelayanan berbasis website yang dapat menampung pengaduan atau keluhan penghuni rumah susun. Dengan adanya masalah tersebut, memunculkan ide bagi kami untuk membantu mempermudah sistem pelayanan yang diberikan oleh pengelola Rumah Susun kepada para penghuni. Oleh karena itu, kami merancang suatu aplikasi yang dapat digunakan untuk mempermudah pelayanan Rumah Susun agar lebih efektif dan efisien. Aplikasi "RUSUN" Berbasis Website dirancang menggunakan metode pengembangan sistem waterfall. Dengan rancang bangun tersebut, diharapkan aplikasi ini dapat memberikan pelayanan menjadi lebih efektif dan efisien, serta penghuni Rumah Susun bisa mengakses pelayanan serta informasi dari mana saja dan kapan saja.
\end{abstract}

Kata kunci: Rumah Susun, Pelayanan, Waterfall

\begin{abstract}
Cinta Kasih Tzu Chi Flats is managed by the private sector. The Flats implements a service management system manually so that there are several obstacles that hinder the service process for apartment residents, namely there is no website-based service system that can accommodate complaints or complaints from residents of the apartment. With this problem, came up with an idea for us to help simplify the service system provided by the apartment manager to the residents. Therefore, we designed an application that can be used to simplify the services of the Flats to be more effective and efficient. Website-based "RUSUN" application is designed using the waterfall system development method. With this design, it is hoped that this application can provide services to be more effective and efficient, and the residents of the Flats can access services and information from anywhere and anytime.
\end{abstract}

Keywords: Flat House, Service, Waterfall

\section{PENDAHULUAN}

\subsection{Latar Belakang Masalah}

$\mathrm{M}$ anusia adalah makhluk sosial yang mempunyai banyak kebutuhan harus dipenuhi, salah satu kebutuhan utama manusia yaitu kebutuhan primer. Kebutuhan primer terdiri dari sandang, pangan dan papan. [1] Semua kebutuhan tersebut menjadi kebutuhan dasar yang amat penting untuk mencukupi kelangsungan hidup manusia. Selain sandang dan pangan kebutuhan papan tidak kalah penting untuk dipenuhi. Papan atau rumah dibutuhkan setiap 
manusia sebagai tempat tinggal atau tempat berlindung bagi keluarganya.

Rumah susun adalah milik perseorangan yang diatur oleh pengelola dari Pengembang saat sebelum dibentuknya PPRS (Perhimpunan Penghuni Rumah Susun) oleh para penghuni rumah susun tersebut. [2] Pembuatan PPRS tertuju supaya para owner ataupun penghuni rumah susun bisa memahami dan melakukan hak serta kewajibannya masing- masing sehingga pengelolaan hunian bersama itu bisa terselenggara dengan baik. Manajemen hak bersama tidak bisa dicoba dengan asal- asalan sebab perihal tersebut menyangkut kebutuhan orang banyak. Salah satu inovasi yang amat berarti pada industri properti merupakan mutu konstruksi serta pula rancangan dari konstruksi dan pelayanan dalam mengatur rumah susun tersebut. Pelayanan yang diberikan oleh rumah susun cinta kasih tzu chi berupa pemberian fasilitas seperti posyandu dan posbindu, serta memfasilitasi pengaduan bagi penghuni rumah susun yang ingin menyampaikan permasalahan yang terjadi di unit rumah susun. Namun, penghuni rumah susun juga diberi beberapa kewajiban untuk dipenuhi, yaitu penghuni rumah susun wajib melapor jika tamu yang bertamu lebih dari 1 x 24 jam. Penghuni rumah susun wajib membayar iuran pemeliharaan lingkungan yang akan digunakan untuk merawat fasilitas yang ada pada lingkungan rumah susun. Ketua RW juga memberikan pelayanan bagi penghuni yang ingin bergabung menjadi anggota Karang Taruna.

Akan tetapi, pelayanan yang ada pada rumah susun cinta kasih tzu chi saat ini tidak memiliki sistem yang memadai, sehingga pelayanan yang diberikan tidak maksimal. hambatan yang dialami oleh manajemen rumah susun Cinta Kasih Tzu Chi - Cengkareng saat ini tidak terdapatnya sistem pelayanan secara online, Perihal semacam ini dapat menyebabkan minimnya kepercayaan penghuni kepada manajemen pada kemampuan yang ada dalam mengelola rumah susun tersebut. untuk memudahkan penghuni memperoleh pelayanan cepat, hingga dapat dihimpun dalam suatu aplikasi. Melihat kondisi saat ini, manajemen pelayanan mengolah dan menyediakan informasi yang tidak memadai, sehingga dibutuhkan nya suatu sistem informasi dalam meningkatkan pelayanan yang bisa membagikan informasi secara up- to- date khususnya proses pengaduan ataupun keluhan yang diajukan oleh penghuni yang bisa dicoba dimana saja dengan memakai jaringan internet.

Dari permasalahan diatas maka penulis membuat "APLIKASI PELAYANAN RUMAH SUSUN PADA RUMAH SUSUN CINTA KASIH TZU CHI BERBASIS WEB” untuk membantu pelayanan yang baik bagi penghuni pada Rumah Susun Cinta Kasih Tzu Chi.

\subsection{Rumusan Masalah}

1. Bagaimana sistem pelayanan rumah susun berbasis web yang dibuat dapat membantu pengelola dan ketua RW dalam memberikan pelayanan yang baik kepada penghuni rumah susun?

2. Bagaimana sistem pelayanan rumah susun yang dibuat dapat meningkatkan kualitas pelayanan penghuni?

\subsection{Batasan Masalah}

1. Aplikasi ini hanya untuk rumah susun cinta kasih tzu chi

2. Aplikasi Rusun yang dikembangkan terdiri dari data penduduk, pengaduan, laporan tamu, daftar posyandu, daftar posbindu, daftar anggota karang taruna, pembayaran iuran pemeliharaan lingkungan.

\subsection{Tujuan Penelitian}

1. Menghasilkan rancangan sistem pelayanan rumah susun yang berfungsi untuk membantu pengelola dan ketua RW dalam memberikan pelayanan yang baik kepada penghuni rumah susun cinta kasih tzu chi. 
2. Mempermudah pengelola dan ketua RW dalam melayani penghuni di rumah susun cinta kasih tzu chi.

3. Mempermudah penghuni rumah susun cinta kasih tzu chi berinteraksi dengan pengelola dan ketua RW dalam pelayanan yang diberikan.

\subsection{Penelitian Terdahulu}

Penelitian ini dilatar belakangi berdasarkan penelitian yang dilakukan Kusuma ferdy setyawan (2019). Dengan judul Sistem Informasi Pengelolaan Rumah Susun (Studi Kasus: PT. Graha Tama Persada Realty), metode untuk perancangan sistem informasi menggunakan metode waterfall. Masalah yang di alami tidak adanya sistem untuk meningkatkan pelayanan dan aduan penghuni secara online, belum adanya sebuah sistem remainder aduan yang sudah di follow up maupun yang sedang dalam proses pengerjaan, dengan tujuan membuat suatu sistem pelayanan untuk memudahkan penghuni membuat laporan atau aduan kepada pengelola rumah susun dan hasil dari penelitian tersebut Meningkatkan efektifitas proses aduan yang dilakukan oleh para penghuni rumah susun. [3]

\section{LANDASAN TEORI}

\subsection{Definisi Rumah Susun}

Menurut UU No 20 Tahun 2011 pada Pasal 1 menuturkan,“ Rumah Susun merupakan bangunan gedung bersusun yang dibentuk dalam sesuatu kawasan, yang dibagi dalam bagianbagian yang distrukturkan secara fungsional dalam arah horizontal ataupun vertikal serta merupakan satuan- satuan yang masing- masing bisa dimiliki serta dipakai secara terpisah, paling utama untuk tempat hunian, yang dilengkapi dengan bagian- bersama, benda- bersama serta tanah- bersama" [4].

\subsection{Definisi Penghuni Rumah Susun}

Pemilik rumah susun serta penghuni rumah susun, diatur dalam Undang- Undang No 16 Tahun 1985 Mengenai Rumah Susun terutama Pasal 1 poin 9 dan poin 10, "dituturkan bahwa yang dimaksud dengan Pemilik merupakan perseorangan ataupun badan hukum yang mempunyai satuan rumah susun yang memenuhi ketentuan sebagai pemegang hak berdasarkan tanah, sedangkan yang dimaksud dengan Penghuni merupakan perseorangan yang bertempat tinggal dalam unit rumah susun" [3].

\subsection{Definisi Pelayanan}

Pelayanan masyarakat mempunyai kedudukan yang amat berarti terlebih lagi vital pada kehidupan ekonomi atau politik. "Pelayanan masyarakat merupakan aspek sangat berarti dalam menambah kualitas hidup sosial didalam masyarakat manapun" (Saragih, 2006). Dalam memberikan pelayanan yang bagus maka butuh dipahami arti sebetulnya dari pelayanan itu", Pelayanan ialah sesuatu cara bantuan pada orang lain dengan cara- cara khusus yang menginginkan sensitivitas dan ikatan interpersonal agar terwujud kepuasan serta keberhasilan" (Boediono, 2003) [5].

Bagi Wasistiono (2001) "pelayanan ialah pemberian pelayanan baik oleh negara, pihak swasta atas nama negara ataupun pihak swasta kepada masyarakat, dengan ataupun tanpa pembayaran untuk penuhi keinginan dan keperluan masyarakat". Bagi S. Lukman( 2004) dalam Sagita (2010),"pelayanan ialah sesuatu kegiatan atau urutan aktivitas yang terjalin dalam interaksi langsung antara seseorang dengan orang lain ataupun mesin dengan cara fisik, serta menyediakan kepuasan konsumen" [6]. 


\subsection{Definisi Software Development Life Cycle}

Software Development Life Cycle yaitu proses menentukan sebuah sistem informasi sanggup mendukung kebutuhan bisnis, mendesain sistem, mengembangkan, dan menyalurkannya ke pengguna. Orang yang bertanggung jawab dalam perancangan sistem informasi ialah analis sistem dimana seseorang sistem analis wajib mampu menganalisa proses bisnis, mengidentifikasi kebutuhan dan desain sistem. Sistem analis bekerja sama dengan seluruh anggota tim proyek sehingga dapat meningkatkan sistem secara tepat serta efisien [7].

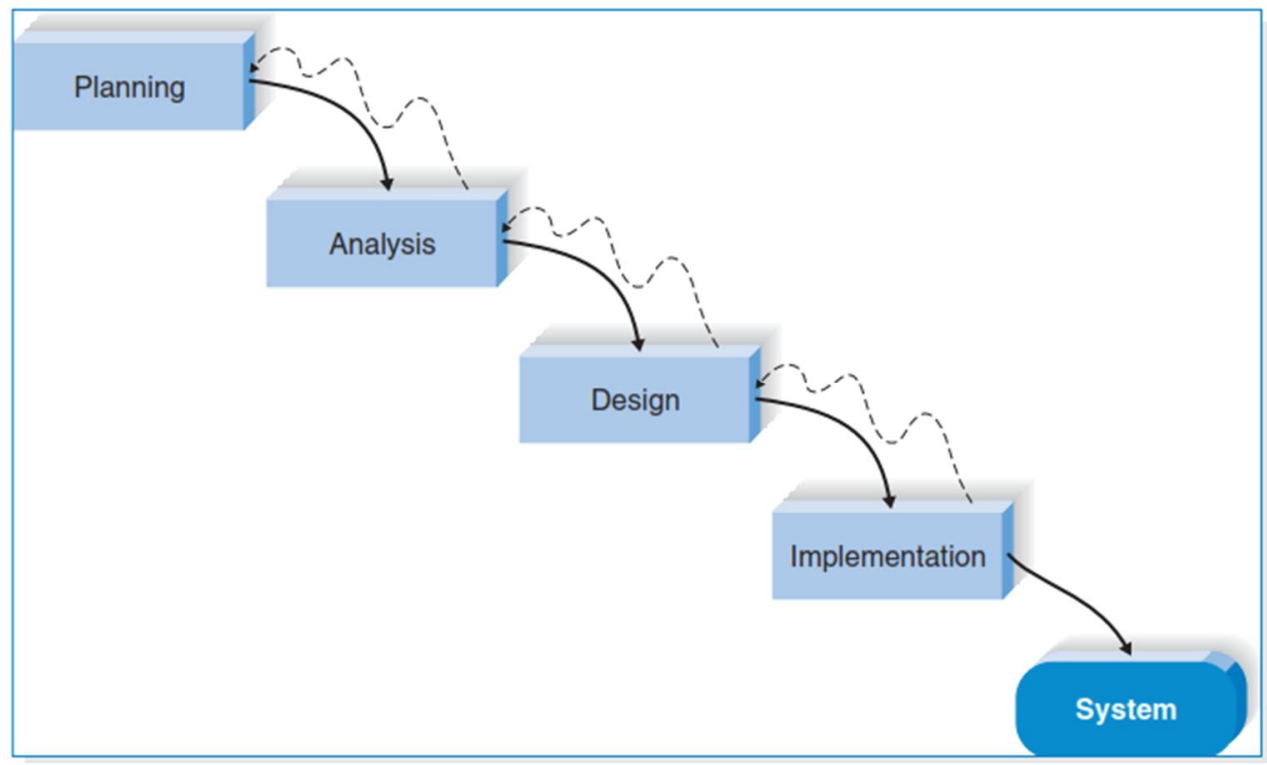

Gambar 1. Watelfall

\subsection{Waterfall}

Waterfall Development merupakan "perangkat lunak sekuensial pada proses pengembangan software di mana perkembangannya mengalir semakin ke bawah (bagaikan air terjun) melalui fase yang wajib dijalani untuk membangun perangkat lunak komputer". Waterfall Model menggunakan pendekatan secara sistematis, untuk pengembangan perangkat lunak pertama diawali dengan spesifikasi klien serta proses yang melalui perencanaan, desain, pengembangan dan perawatan dari perangkat lunak yang telah selesai [7].

\subsection{Pieces}

Dalam menganalisa sesuatu sistem, biasanya hendak dilakukan sebagian evaluasi antara lain yaitu "kinerja, informasi, ekonomi, keamanan aplikasi, efisiensi dan pelayanan klien. Analisa ini disebut dengan PIECES Analisa". Analisa PIECES ini amat berarti untuk dicoba saat sebelum meningkatkan sesuatu sistem informasi sebab dalam analisa ini hendak ditemui beberapa permasalahan penting ataupun permasalahan yang bersifat indikasi dari kasus utama [8].

\subsection{Framework Laravel}

Laravel ialah "framework yang digunakan untuk web development pada PHP. laravel ialah suatu framework yang lebih menekankan pada kesederhanaan dan fleksibilitas dari perspektif desainnya" (Aminudin, 2015). begitu juga framework yang yang lain, laravel dibangun dengan dasar MVC (Model- View- Controller). Laravel jadi salah satu framework favorit programmer PHP untuk membuat aplikasi- aplikasi yang lebih baik serta dinamis. laravel jadi framework terbaik pada tahun 2014 [9]. 


\subsection{Vue.js}

Vue (dibaca: view) merupakan salah satu dari sekian banyak Pustaka (library) pada bahasa pemrograman Javascript yang dipakai untuk membuat tampilan antarmuka pengguna (user interface) dari suatu aplikasi berbasis website khususnya Single Page Application (SPA). Vue sebagaimana Javascript, memang awal mulanya didesain untuk kebutuhan website, namun seiring kemajuan teknologi yang mendukung Javacript, sehingga saat ini Vue juga mulai dapat dipakai untuk meningkatkan aplikasi berbasis desktop dan mobile [10].

Vue. js ialah suatu Framework JavaScript progresif yang digunakan untuk membuat tampilan user interface dengan memusatkan pada arsitektur MVC. Vue. js ialah proyek opensource dengan sertifikat MIT yang dicetuskan oleh Evan You pada bulan Februari 2014. Fitur yang ditawarkan oleh Vue. js ialah System Reactive Informasi Binding yang berfungsi supaya data dan DOM tetap tercampur bersama- sama [11].

\subsection{Single Page Application (SPA)}

Single Page Application ialah aplikasi yang beroperasi pada browser yang tidak membutuhkan reload page saat dijalankan. Yang membedakan SPA dengan Multi Page Application( Traditional Page Aplication) merupakan Single Page Application hanya menerapkan load pada satu halaman dari server setelah itu metode routing yang umumnya ditangani oleh server disaat ini diberatkan pada klien [12].

Single Page Application (SPA) menggunakan satu laman web sebagai tampilan dari aplikasi, hingga bisa kurangi bobot kegiatan dari server serta browser alhasil menciptakan kinerja aplikasi web semacam aplikasi Desktop dengan metode me- Rendering semua informasi yang sudah dimasukkan, sesudah itu diterjemahkan dalam bentuk output. Dalam studi memberi tahu "Single Page Application (SPA) is composed ofindividual components that can be replaced/ updatedindependently, without refreshing/ reloading whole page so that the entire page needs not to be reloaded on every user action". Aplikasi Laman Tunggal( Single Page Application) terdiri dari bagian individual yang dapat ditukar ataupun diperbaharui dengan cara mandiri, tanpa merefresh atau mereload laman, alhasil laman tidak wajib dimuat ulang pada tiap tindakan oleh pemakai [13].

\section{HASIL DAN PEMBAHASAN}

\subsection{Metode Pengumpulan Data}

Penulis melakukan pengumpulan data yang menjadi kebutuhan sistem yang akan dibangun melalui beberapa tahap seperti observasi dengan melakukan pemantauan langsung terhadap proses sistem yang sedang berjalan untuk memperoleh informasi yang akan di implementasikan kedalam sistem. Wawancara (interview) dilakukan dengan ketua RW setempat dan Pengelola rumah susun kemudian studi kepustakaan yaitu dengan melakukan pengumpulan data dari sumber-sumber jurnal online dan rujukan penelitian yang berkaitan dengan riset ini. Setelah itu dilakukan proses analisis sistem yang sedang berjalan, sehingga proses pembangunan sistem sesuai dengan prosedur yang di inginkan. 


\subsection{Analisa PIECES}

\begin{tabular}{|l|l|l|}
\hline Pieces & Sistem Yang Sedang Berjalan & Sistem Yang Diusulkan \\
\hline Performa & $\begin{array}{l}\text { Pada sistem rumah susun ini semua dilakukan } \\
\text { secara manual yaitu berkunjung ke pengelola } \\
\text { dan Ketua RW }\end{array}$ & $\begin{array}{l}\text { Pada sistem yang diusulkan akan } \\
\text { lebih memudahkan penghuni tanpa } \\
\text { harus berkunjung }\end{array}$ \\
\hline Informasi & $\begin{array}{l}\text { Pada sistem ini informasi berkaitan dengan } \\
\text { rumah susun dan pelayanan dengan } \\
\text { menggunakan papa pengumuman }\end{array}$ & $\begin{array}{l}\text { Pada sistem yang diusulkan } \\
\text { informasi terkait rumah susun dan } \\
\text { pelayanan bisa diakses darimana } \\
\text { saja }\end{array}$ \\
\hline Ekonomi & $\begin{array}{l}\text { Pada sistem ini menggunakan media kertas, } \\
\text { sehingga terjadi pemborosan }\end{array}$ & $\begin{array}{l}\text { Pada sistem yang diusulkan data } \\
\text { tersimpan dalam database sehingga } \\
\text { mengurai pemborosan }\end{array}$ \\
\hline Kontrol & $\begin{array}{l}\text { Pada sistem ini control data masih secara } \\
\text { manual, yang kemungkinan data mudah hilang }\end{array}$ & $\begin{array}{l}\text { Pada sistem yang diusulkan user } \\
\text { dapat dengan mudah untuk kontrol } \\
\text { data, karena data dalam bentuk } \\
\text { digital sehingga mudah } \\
\text { cadangkan }\end{array}$ \\
\hline Efisiensi & $\begin{array}{l}\text { Pada sistem ini pendataan pelayanan masih } \\
\text { dilakukan secara manual sehingga pelayanan } \\
\text { dapat dilakukan di jam tertentu }\end{array}$ & $\begin{array}{l}\text { Pada sistem yang diusulkan ini } \\
\text { pendataan pelayanan } \\
\text { dilakukan dimana saja dan kapan } \\
\text { saja }\end{array}$ \\
\hline Layanan & $\begin{array}{l}\text { Pada sistem ini pelayanan yang manual } \\
\text { membuat waktu tunggu menjadi lama }\end{array}$ & $\begin{array}{l}\text { Pada sistem yang diusulkan dapat } \\
\text { mempercepat semua pelayanan } \\
\text { yang diberikan }\end{array}$ \\
\hline
\end{tabular}

\subsection{Use Case Sistem Usulan}

Dalam perancangan sistem ini, penyusun membuat use case untuk menjelaskan tahap dalam proses yang dilakukan oleh sistem pada gambar 2 dibawah ini. 


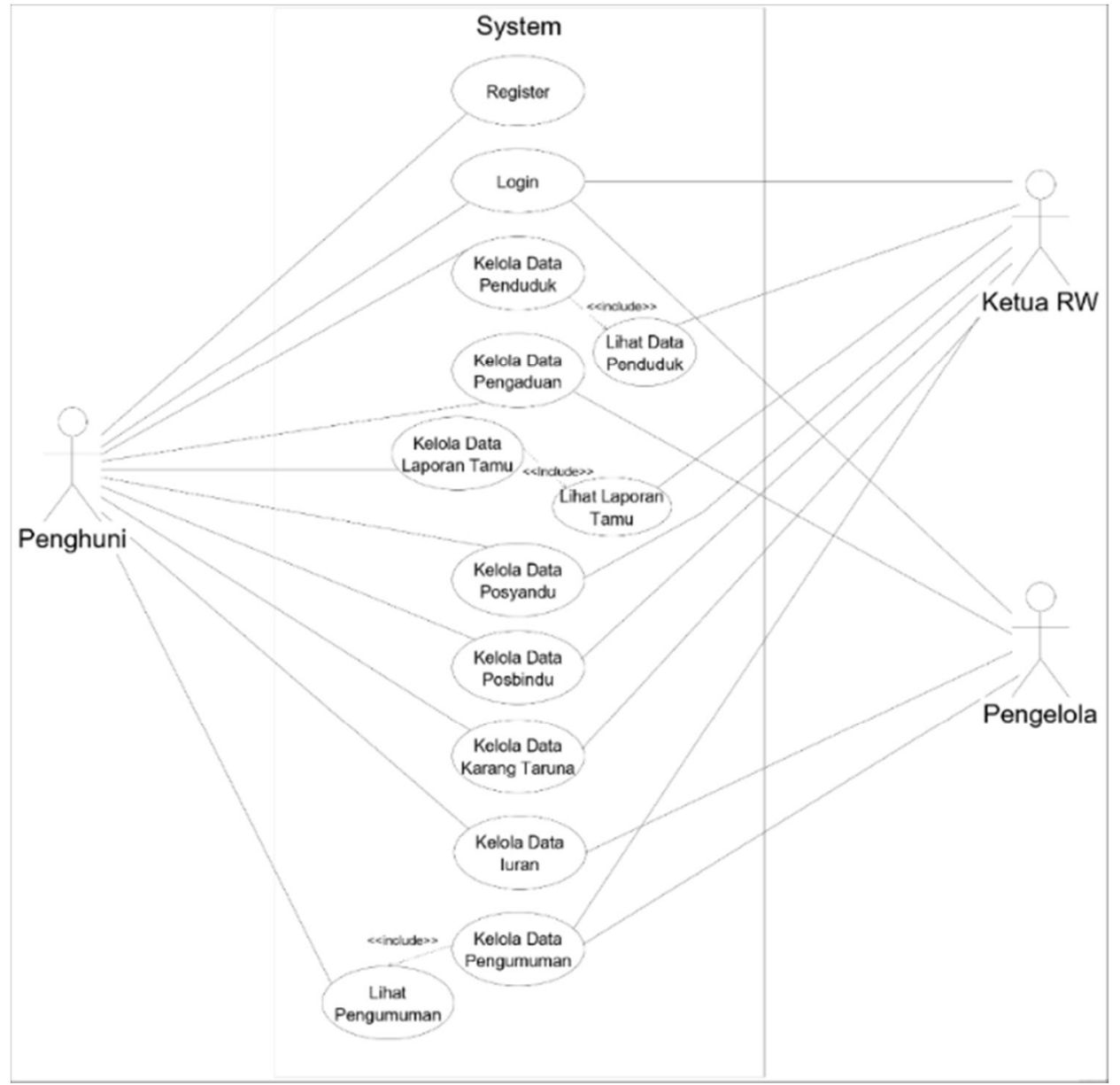

Gambar 2. Use Case Sistem Usulan

\subsection{Kebutuhan Fungsional}

Kebutuhan Fungsional ialah kebutuhan yang berisi proses yang nantinya dilakukan oleh sistem.

1. Sistem harus mampu menginput data penduduk

- 1 data kartu keluarga memuat banyak NIK

- Pengguna memasukkan data penduduk sesuai kartu keluarga

- Pengguna bisa menambah data anggota keluarga

2. Sistem harus mampu menginput data pengaduan

- Pengguna melakukan pengaduan sesuai kebutuhan

- Sistem dapat menampilkan status pengaduan

3. Sistem dapat menginput data laporan tamu

- Pengguna dapat melaporkan tamu yang berkunjung lebih dari 1x24 jam

- Pengguna mengisi form laporan tamu

- Sistem dapat mengupload foto ktp

4. Sistem dapat melakukan pendaftaran Posyandu dan Posbindu

- Pengguna dapat mendaftarkan keluarga yang ingin mengikuti kegiatan posyandu

- Sistem hanya dapat mendaftarkan keluarga yang sudah didaftarkan di data penduduk

5. Sistem dapat melakukan pendaftaran keanggotaan karang taruna

- Pengguna dapat mendaftarkan keluarga sebagai anggota karang taruna 
6. Sistem dapat melakukan transaksi pembayaran iuran lingkungan

- Pengguna dapat melakukan pembayaran dengan cara transfer

- Kemudian mengupload bukti transfer ke sistem

- Sistem menampilkan status pembayaran

7. Sistem dapat manampilkan pengumuman

- Pengguna dapat melihat pengumuman yang dibuat

\subsection{Kebutuhan Non Fungsional}

Non Fungsional merupakan kebutuhan pendukung yang dimiliki sistem, yaitu kebutuhan operasional, keamanan, informasi, kinerja, user dan tampilan

1. Kebutuhan Keamanan

- Aplikasi dilengkapi dengan username dan password

2. Operasional Hardware

- Hardware: Har disk drive 250 Giga byte, RAM 2 Giga byte

- Jaringan internet

3. Operasional Software

- Sistem Operasi Windows 10

4. Kebutuhan Informasi

- Terdapat informasi berkaitan dengan rumah susun dan pelayanan rumah susun

5. Kebutuhan Pengguna

- Admin

- User Penghuni

- User Pengelola

- User RW

\subsection{Class Diagram}

Adapun relasi tabel pada perancangan basis data[14] aplikasi untuk pelayanan Rumah Susun Cinta Kasih Tzu Chi terlihat pada gambar 3 dibawah ini

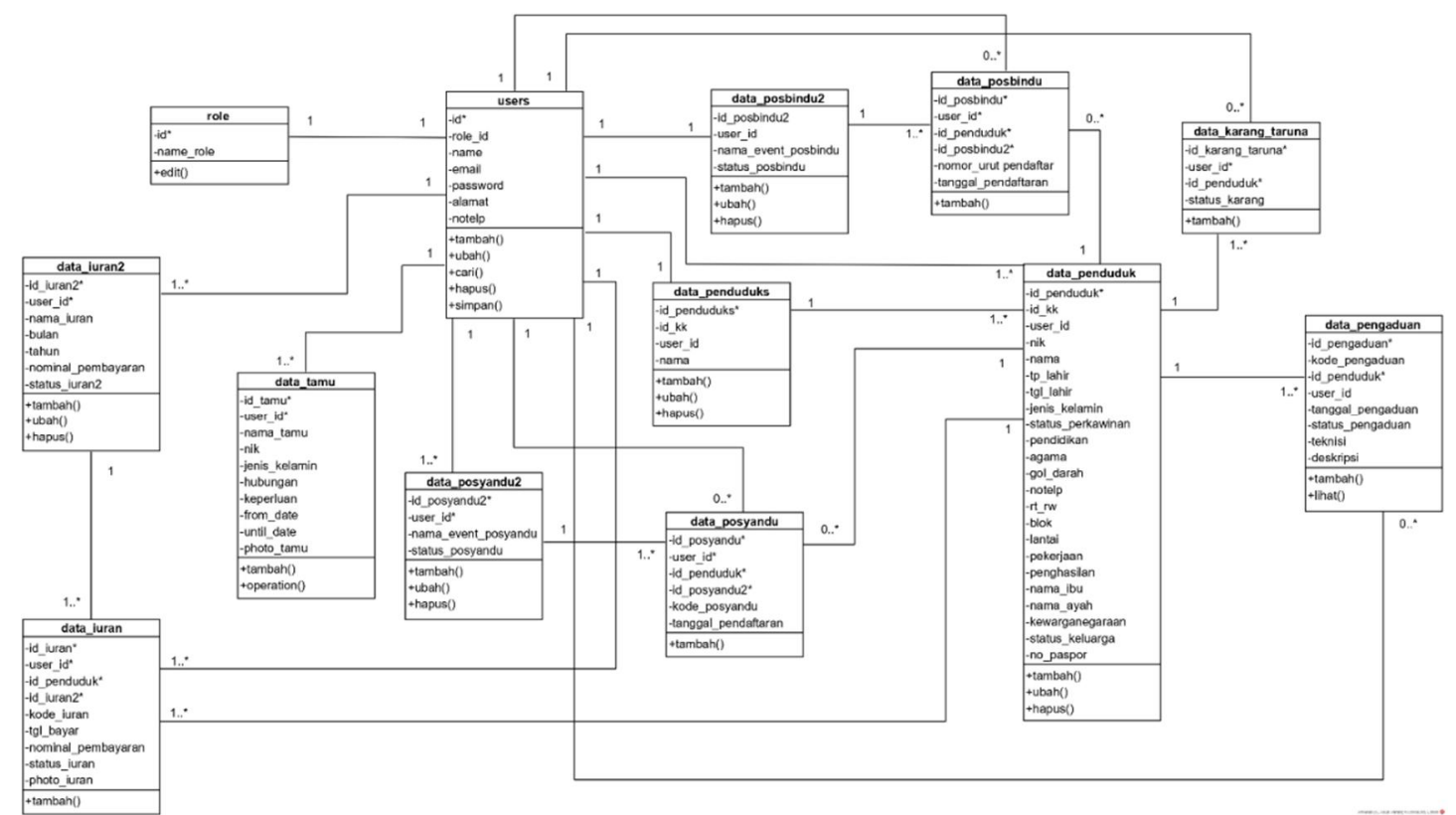

Gambar 3. Class Diagram

Mardiansah, et., al [Aplikasi Pelayanan Rumah Susun Berbasis Website (Studi Kasus: Rumah Susun Cinta Kasih Tzu Chi) 


\subsection{Implementasi}

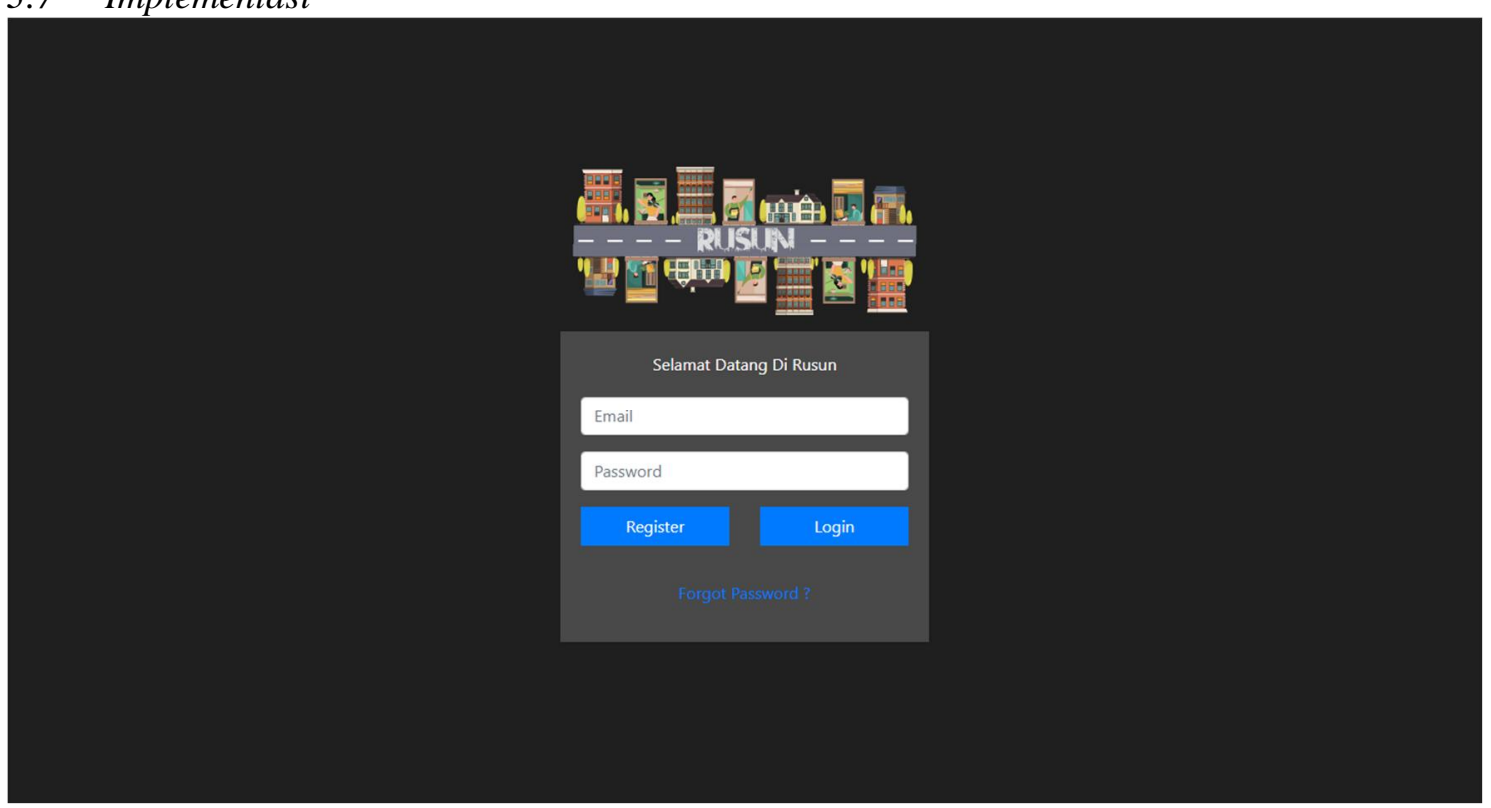

Gambar 4. Halaman Login

Gambar 4 ini adalah halaman antarmuka login yang akan digunakan pada user untuk masuk ke dalam sistem.

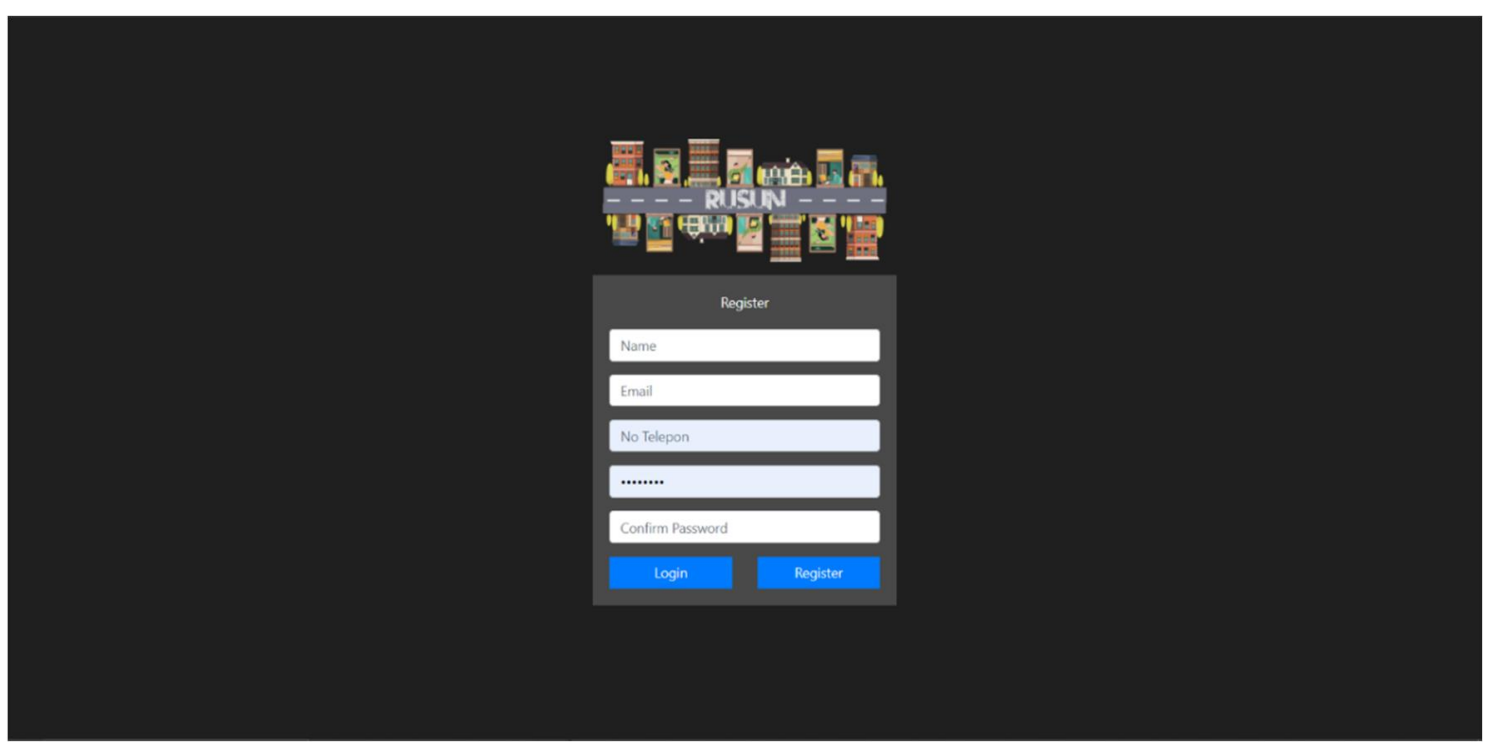

Gambar 5. Halaman Register

Gambar 5 ini merupakan halaman antarmuka register yang akan digunakan untuk penghuni yang tidak memiliki akun pada sistem. 


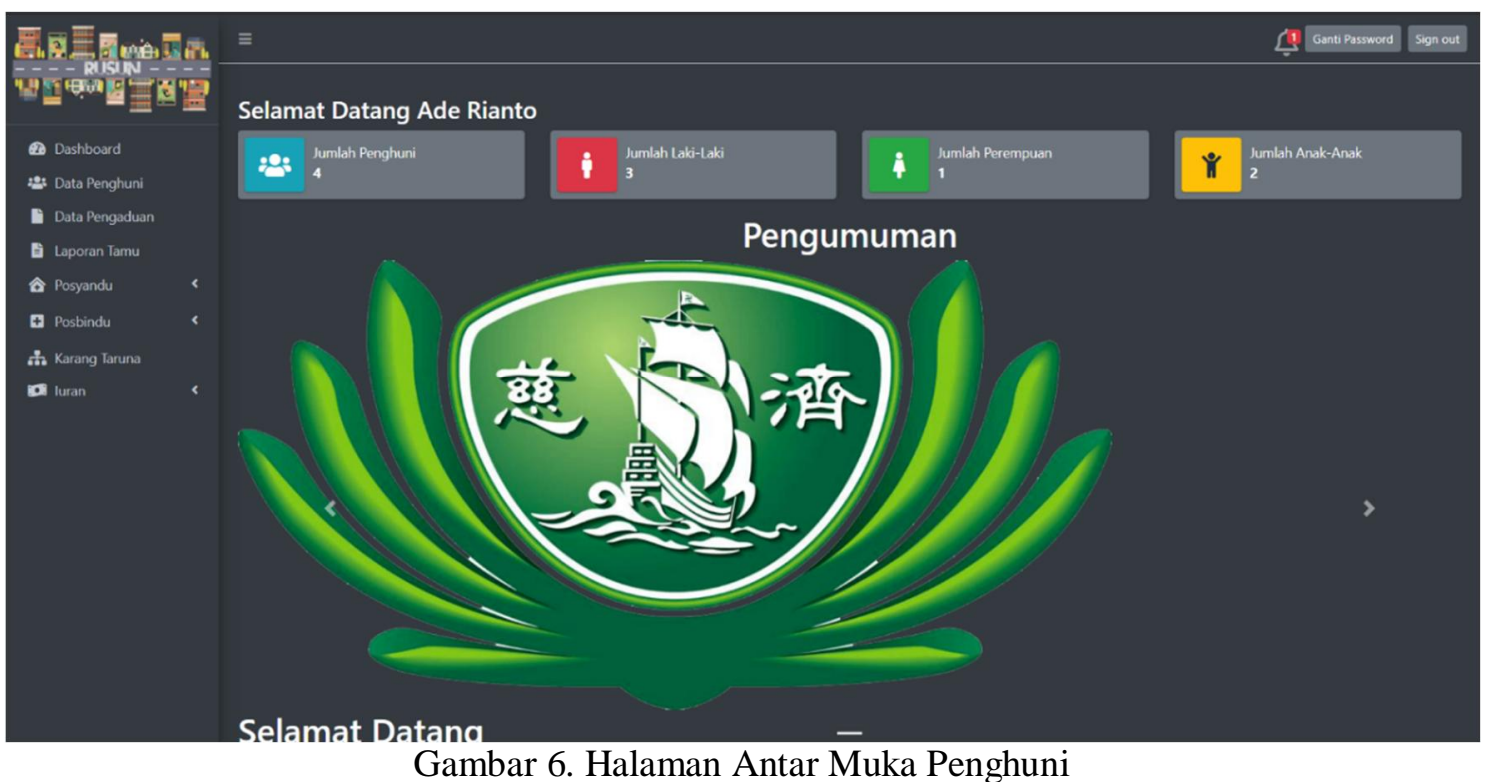

Gambar 6 merupakan halaman antarmuka penghuni, penghuni dapat mengakses fitur dashboard, data penghuni, data pengaduan, laporan tamu, daftar posyandu, daftar posbindu, daftar anggota karang taruna, hingga membayar iuran

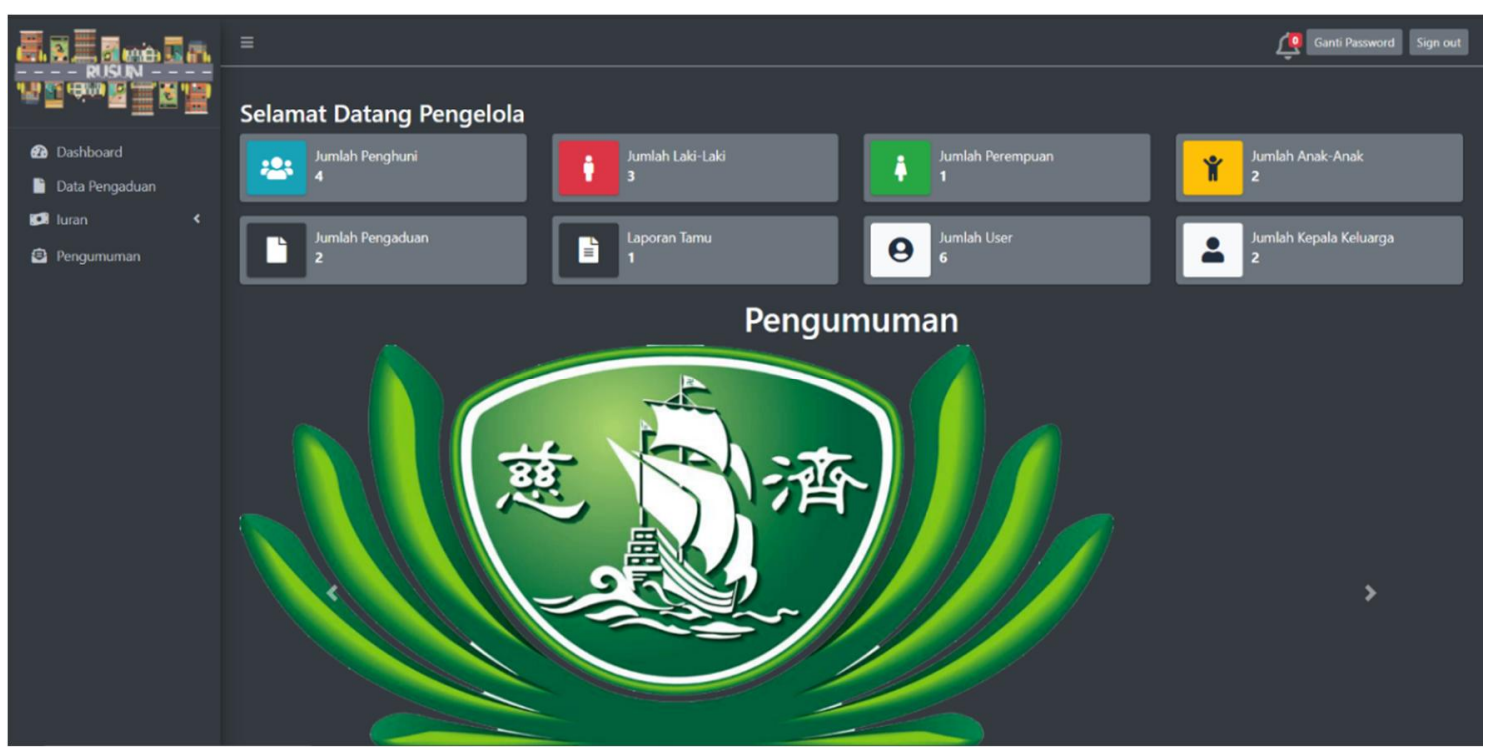

Gambar 7. Halaman Antar Muka Pengelola

Gambar 7 ini merupakan halaman antarmuka pengelola, pengelola dapat mengakses fitur dashboard, mengolah data pengaduan yang dilaporkan oleh penghuni, mengolah data iuran dan mengolah pengumuman. 


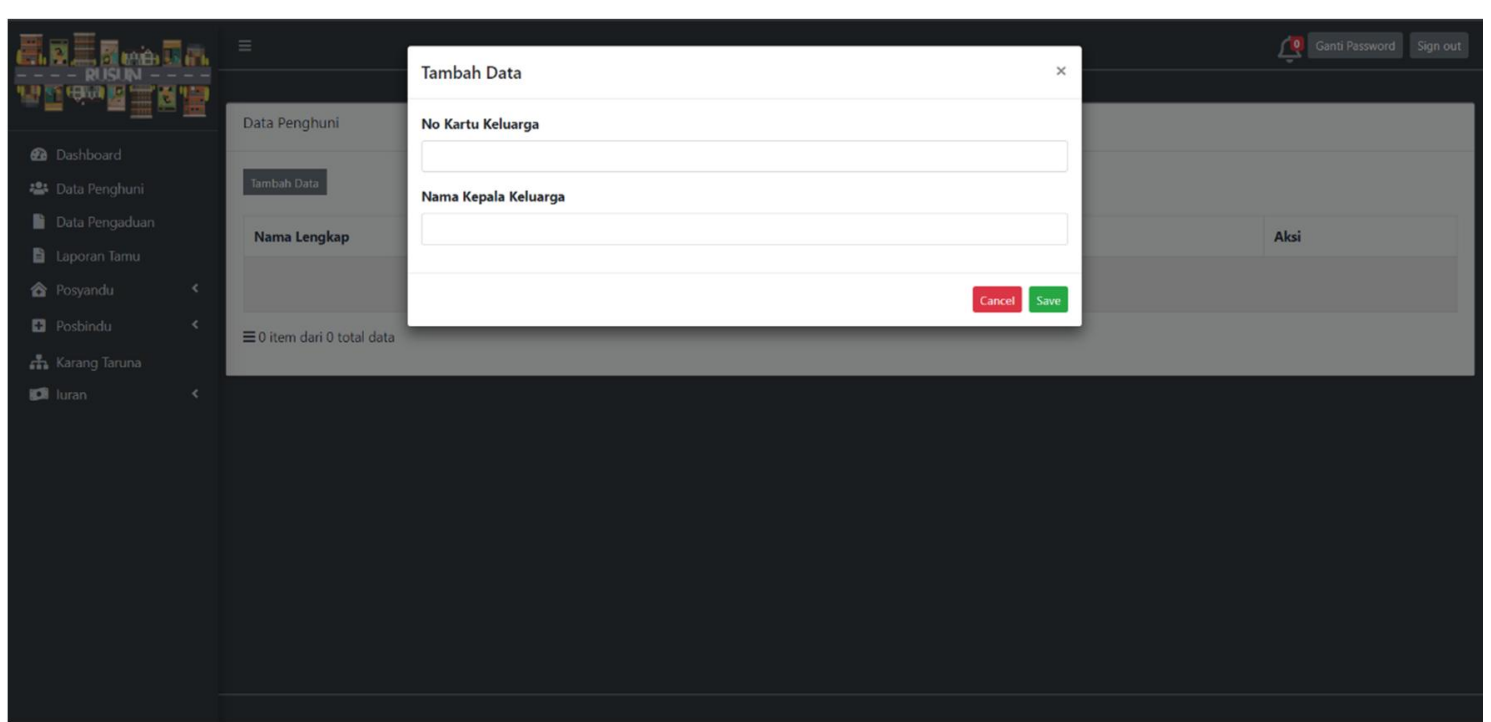

Gambar 8. Input Form Nomor Kartu Keluarga

Gambar 8 merupakan Halaman input form nomor Kartu Keluarga pada user penghuni untuk mendaftarkan nomor kartu keluarga, sehingga dapat membuka semua fitur yang ada pada aplikasi.

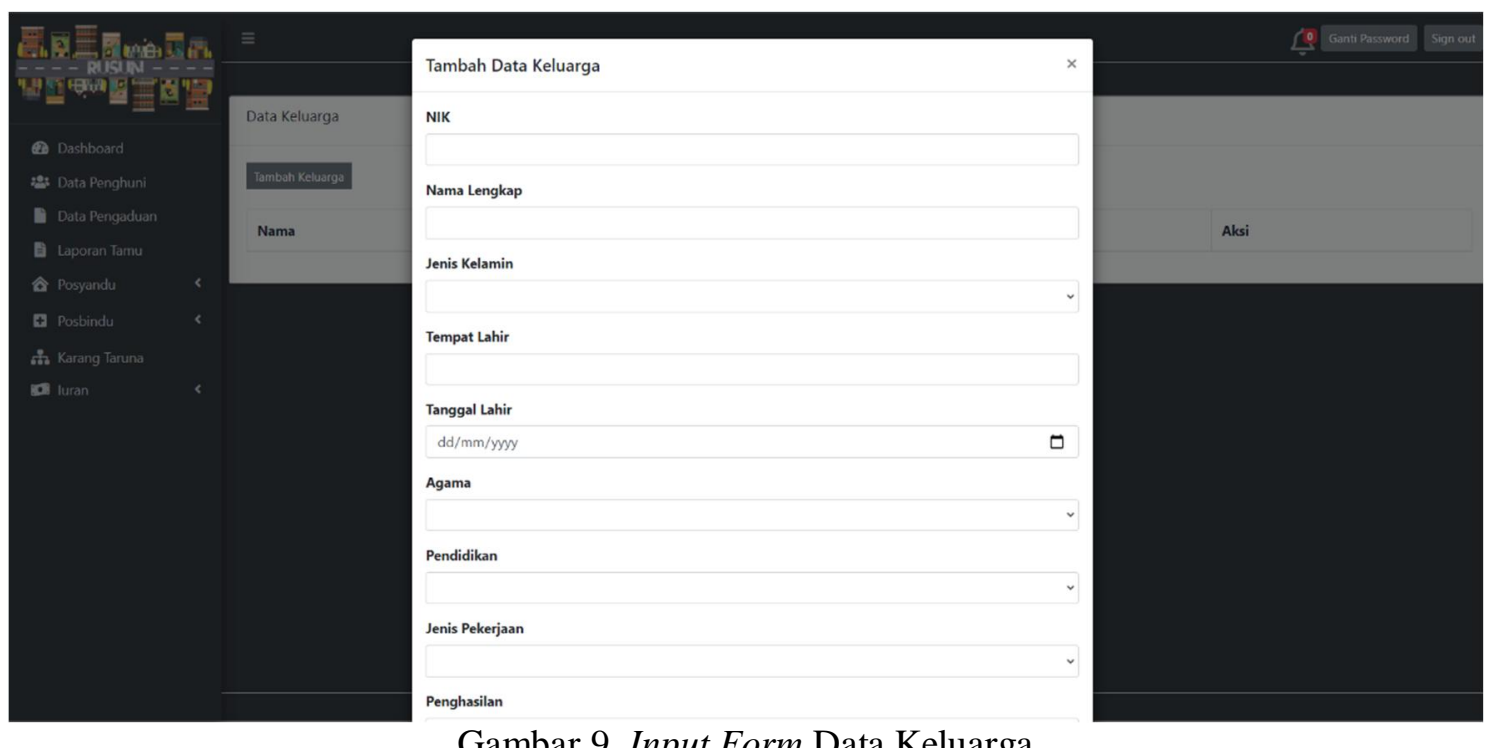

Gambar 9. Input Form Data Keluarga

Gambar 9 merupakan halaman input form data keluarga pada user penghuni, penghuni dapat mendaftarkan keluarganya pada aplikasi sehingga dapat memanfaatkan semua fitur yang ada pada aplikasi. 

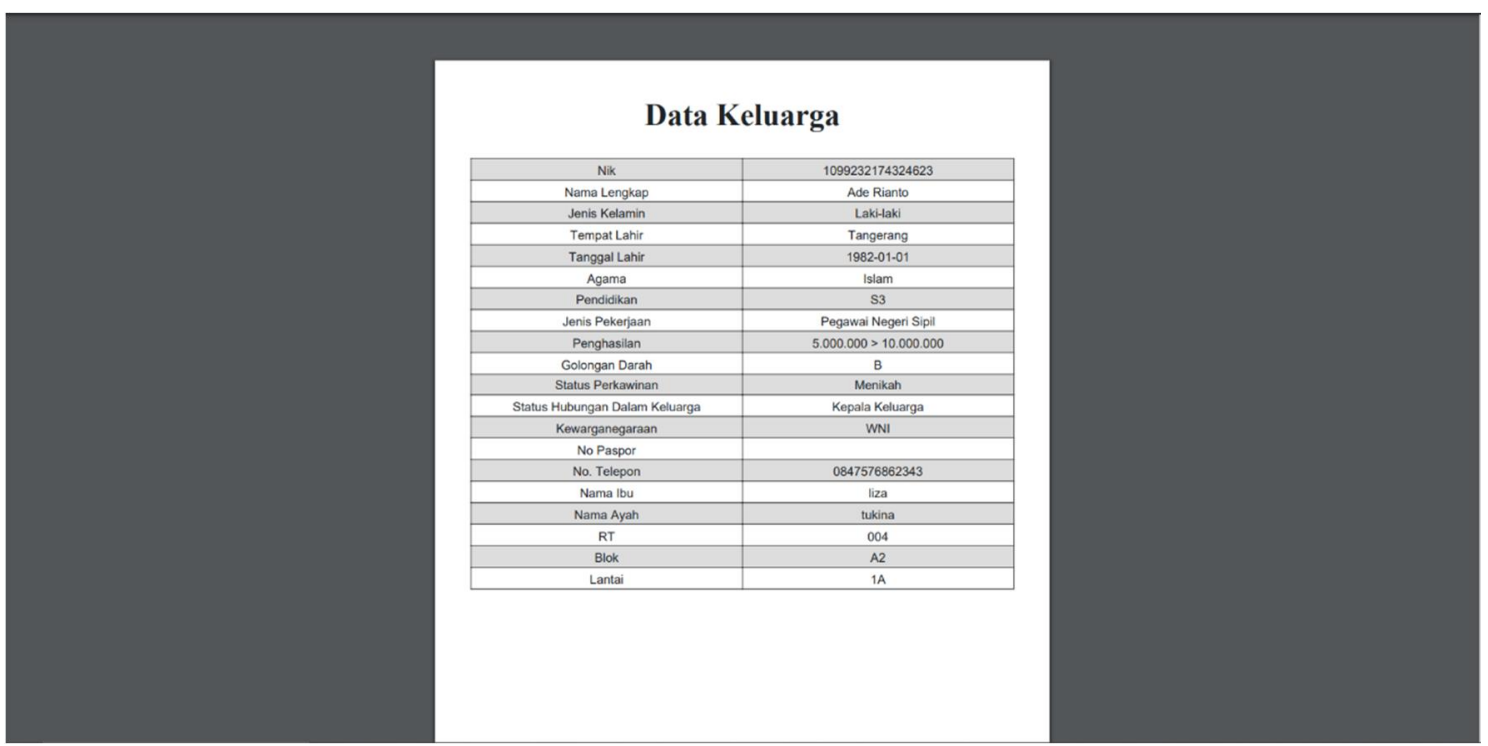

Gambar 10. Output Data Keluarga

Gambar 10 merupakan halaman output dari data keluarga yang sudah di daftarkan oleh penghuni

\section{KESIMPULAN}

Berdasarkan hasil dari analisis dan implementasi yang telah dilakukan, dengan aplikasi RUSUN dapat ditarik kesimpulan sebagai berikut:

1. Aplikasi pelayanan rumah susun yang dirancang menghasilkan pengaduan secara online dimana penghuni tidak perlu menulis surat, dan penghuni dapat langsung memantau status pengaduan yang telah dibuat.

2. Aplikasi pelayanan rumah susun juga merancang form inputan data penghuni rumah susun cinta kasih tzu chi, sehingga memudahkan ketua RW untuk menjalankan pelayanan yang di berikan untuk penghuni.

3. Aplikasi pelayanan rumah susun yang dirancang menghasilkan dan mempermudah pembayaran iuran pemeliharaan lingkungan secara online dimana penghuni tidak perlu dating ke kantor pengelola secara langsung. Penghuni juga dapat melihat status pembayaran tersebut.

4. Informasi seputar pelayanan pemnghuni tersampaikan dengan baik dengan adanya aplikasi pelayanan rumah susun.

\section{SARAN}

Rancangan aplikasi RUSUN masih memiliki kekurangan yang dapat diperbaiki maupun dilengkapi mengingat aplikasi ini masih sederhana, saran untuk pengembangan sistem selanjutnya yaitu:

1. Aplikasi RUSUN ini masih berbasis website, berharap adanya pengembangan dalam pembuatan aplikasi RUSUN berbasis mobile platform.

2. Perlu adanya verifikasi bahwa user yang mendaftar benar sebagai penghuni Rumah Susun Cinta Kasih Tzu Chi. 
3. Perlu ditambahkan riwayat pemeriksaan pada menu Posyandu dan Posbindu.

4. Pada menu Karang Taruna dapat ditambahkan rencana kegiatan yang akan dijalankan oleh anggota Karang Taruna.

\section{UCAPAN TERIMA KASIH}

Penulis mengucapkan terima kasih kepada Pengelola Rumah susun cinta Kasih Tzu Chi dan ketua RW yang memperbolehkan penulis melakukan penelitian dan uji sistem di lingkungan rumah susun, serta Ibu Anita Ratnasari, S.Kom, M.Kom sebagai dosen pembimbing yang telah membimbing penulis sampai akhir.

\section{DAFTAR PUSTAKA}

[1] F. Sofian, 2020, "Tinjauan Yuridis Atas Wanprestasi Dalam Perjanjian Sewa-Menyewa Rumah yang Dibuat Secara Lisan,"

[2] _ . 1985, "Undang-Undang Republik Indonesia Nomor 16 Tahun 1985 Tentang Rumah Susun."

[3] K. F. Setyawan. 2019, “Sistem Informasi Pengelolaan Rumah Susun,” Universitas Mercu Buana.

[4] _. 2011, "Undang-Undang Republik Indonesia Nomor 20 Tahun 2011 Tentang Rumah Susun.”

[5] E. R. Nainggolan And Susafa'ati. 2018, "Rancang Bangun Sistem Informasi Pelayanan Rukun Warga Pada Rusunawa Pesakih Jakarta Barat,” Semin. Nas. Ilmu Terap. (Sniter 2018)- Univ. Widya Kartika.

[6] J. Sundari. 2016, "Sistem Informasi Pelayanan Puskesmas Berbasis Web," Ijse - Indones. J. Softw. Eng., Vol. 2.

[7] A. Dennis, B. Wixom, and R. Roth. 2012, System Analysis and Design by Alan Dennis 5th Edition.

[8] I. D. Mumpuni And W. A. Dewa, "Analisis dan Pengembangan Sistem Self Services Terminal (Sst) Dengan Pendekatan Pieces pada STMIK Pradnya Paramita Malang," J. Ilmu Komput. dan Teknol. Inf., Vol. 9, 2017.

[9] K. Fahriya And A. I. Nurhidayat. 2018, "Rancang Bangun Simawa (Sistem Informasi Rusunawa) Berbasis Web Application Menggunakan Framework Laravel (Studi Kasus: Universitas Negeri Surabay)," J. Manaj. Inform., Vol. 8.

[10] H. Mukhlasin and M. Azamuddin. 2018, Vue.Js - The Progressive Javascript Framework.

[11] I. K. A. H. Putra, D. Pramana, and N. L. P. Srinadi. 2019, "Sistem Manajemen Arsip Menggunakan Framework Laravel dan Vue.Js (Studi Kasus: Bpkad Provinsi Bali),” J. Sist. dan Inform., Vol. 13, P. 2.

[12] J. Gunawan And I. Gunawan, "Teknologi Single Page Application (Spa).” 2018, Https://Socs.Binus.Ac.Id/2018/12/06/Teknologi-Single-Page-Application-Spa/ (Accessed Nov. 08, 2020). 
[13] P. L. L. Belluano. 2018, “Pengembangan Single Page Application pada Sistem Informasi Akademik,” Ilkom, Vol. 10, P. 1.

[14] T. Mufizar, C. R. Hidayat, And W. Kamaludin. 2018, "Sistem Informasi Terintegrasi Untuk Pengelolaan Rusunawa STMIK Tasikmalaya,” Semin. Nas. Ilmu Terap. (Sniter 2018)- Univ. Widya Kartika. 